\title{
Effects of dietary supplementation of Chinese herb medicine mixture on rumen fermentation, nutrient digestion and blood profile in goats
}

\author{
S.P. Wang ${ }^{\#} \&$ W.J. Wang \\ Rongchang Campus of Southwest University, Chongqing 402460, P.R. China
}

(Received 17 November 2014; Accepted 20 June 2016; First published online 6 August 2016)

\begin{abstract}
Copyright resides with the authors in terms of the Creative Commons Attribution 2.5 South African Licence.
See: http://creativecommons.org/licenses/by/2.5/za

Condition of use: The user may copy, distribute, transmit and adapt the work, but must recognise the authors and the South African Journal of Animal Science.
\end{abstract}

\begin{abstract}
Twenty adult goats, fitted with ruminal cannulae, were used to investigate the effects of dietary supplementation of Chinese herbal medicine ( $\mathrm{CHM}$ ) mixtures on rumen fermentation, nutrient digestion and blood profiles. The wethers were assigned equally to one of the two dietary treatments according to a randomized controlled trial design. One dietary treatment was the basal diet, while the other was the $\mathrm{CHM}$ mixture diet consisting of the basal diet and the CHM mixture. Chinese Mosla, Atractylodes rhizome, Officinal Magnolia bark, white hyacinth bean and Liriope root tuber were mixed with a weight ratio of 8:4:4:4:5 to make up the CHM mixture. This mixture was added to the basal diet at $15 \mathrm{~g} / \mathrm{kg}$ feed. The dietary supplementation of the mixture increased ruminal fluid concentrations of acetate, butyrate and total volatile fatty acids, and the ruminal activities of avicelase, carboxymethyl cellulase, cellobiase and xylanase. It also improved the ruminal effective degradability of dry matter, organic matter and amylase-treated ash-free neutral detergent fibre from the forage, apparent total tract digestibility of gross energy, dry matter, organic matter, crude protein, amylase-treated ash-free neutral detergent fibre, ash-free acid detergent fibre and calcium. Whole blood $\mathrm{pH}$ and concentrations of actual bicarbonate, buffer excess and magnesium ion, plasma concentrations of leptin, total protein, albumin, globulin, C-reactive protein, immunoglobulin A/G/M and complement $3 / 4$ increased. Furthermore, plasma activities of nitric oxide synthase, glutathione peroxidase and total superoxide dismutase and plasma total antioxidative capacity increased. However, plasma concentrations of adrenocorticotropic hormone, aldosterone, cortisol, glucose, urea nitrogen and lactic acid and plasma activities of alanine transaminase, creatine kinase and lactate dehydrogenase decreased. These results indicated that the dietary supplementation of the CHM mixture exerted some positive regulating effects on the nervous system, the endocrine system and the immune system of goats, thus improving the functions of immunity and antioxidation, as well as the digestion and metabolism of nutrients. However, the CHM mixture did not affect their rumen fermentation patterns.
\end{abstract}

Keywords: Chinese herbal medicine, rumen environmental parameter, digestibility, blood indicator, ruminant

\# Corresponding author: wangshuiping1979@sina.com

\section{Introduction}

In China, goats are maintained mainly on high roughage-based diets with limited access to concentrate supplements. This results in low production performance and inferior meat quality. Meanwhile, the use of antibiotic feed additives has been banned in ruminant nutrition in China (MOA, 2004). Consequently, alternatives have to be introduced to manipulate ruminal fermentation, promote feed efficiency and animal growth, and prevent, control and treat diseases. Chinese herbal medicine (CHM) has been suggested as a replacement for antibiotics. The use of herbal medicine in China is an ancient yet living tradition with a sound philosophical, experiential and experimental basis. Although the mechanism of the way in which CHM works is not entirely compatible with the concepts of modern medicine, more than 200 plants have been identified and used in the livestock industry (Lu, 2011). According to the theories of modern pharmacology and nutriology, CHM contains a variety of biologically active substances, such as antibacterial properties, alkaloids, polysaccharides, glycosides, essential oils, tannins, organic acids and unknown growthregulatory factors, as well as nutrients, such as protein, amino acids, carbohydrates, fat, minerals, vitamins and pigments (Liu \& Xu, 2011). Consequently, the bioactivities of a specific CHM are defined by the interactions among a large number of components rather than any specific component. Thus, CHM mixtures consist of more than one CHM and can bring about diversely biological functions that are completely different from those of any ingredients (ChPC, 2010). In China, the application of a mixture of CHM always prevails 
over a single CHM. From the perspective of traditional Chinese medicine principles, a balance should be achieved between a CHM mixture and the body via a compromise or neutralization of certain active substances in the CHM. This mixture could reinforce therapy effects to acclimate to the development of complex diseases, and relieve or eliminate unfavourable effects of a single CHM caused by toxic or extremely potent components (ChPC, 2010). According to the principia of principal, associate, adjuvant and messenger in Chinese medical theory, five types of CHM were used to compose a mixture with various proportions, namely Chinese Mosla, Atractylodes rhizome, Officinal Magnolia bark, white hyacinth bean and Liriope tuber (ChPC, 2010; Liu \& Xu, 2011). Based on Chinese ethnoveterinary medicine, the researchers hypothesized that this mixture might exert positive or negative influences on the alimentary and immune systems of goats. Therefore, the aim was to study the effects of dietary supplementation of this CHM mixture on rumen fermentation, nutrient digestion and blood profile in goats.

\section{Materials and Methods}

Five types of CHM were used in this study, namely the dried aerial parts of Chinese Mosla (Mosla chinensis) (xiāng rú in Chinese); dried Atractylodes rhizome (Atractylodes lancea) (nán cāng zhú); the dried stem, root and branch bark of Officinal Magnolia bark (Magnolia officinalis) (hòu pò); the dried ripe seeds of white hyacinth bean (Dolichos lablab) (bái biăn dòu); and the dried tubers of Liriope. These products are readily available in traditional Chinese medicine markets in China, and were purchased at the Rongchang County Hospital of Traditional Chinese Medicine in Chongqing City, southwestern China, for this study. They are all commercially available as dried raw material. All plant material was air-dried at $40{ }^{\circ} \mathrm{C}$ and coarsely ground to pass through a 2.5-mm screen. Chinese Mosla, Atractylodes lancea, Officinal Magnolia bark, white hyacinth bean and Liriope tuber were mixed equally at a weight ratio of 8:4:4:4:5 to make up the mixture. The CHM mixture was preserved in tightly closed plastic jars that were stored in a dry, dark cool place. After mixing, $1 \mathrm{~kg}$ sample was randomly collected and finely milled using a 1-mm screen to analyse dry matter (DM), gross energy (GE), organic matter (OM), crude protein (CP), amylase-treated ash-free neutral detergent fibre (aNDFom), ash-free acid detergent fibre (ADFom), ether extract (EE), calcium (Ca) and phosphorus $(P)$ contents (Table 1). Gross energy was measured with an isoperibol bomb calorimeter (XRY$1 \mathrm{C}$, Henghe Instrument Co, Changsha, China) with benzoic acid as a standard. The DM was determined as loss of weight after drying a $2 \mathrm{~g}$ aliquot of each sample for $24 \mathrm{~h}$ at $105{ }^{\circ} \mathrm{C}$ (AOAC, 2005). The OM was calculated as the difference between DM and ash contents, with ash quantified by combustion at $550{ }^{\circ} \mathrm{C}$ for $5 \mathrm{~h}$ in a muffle furnace (AOAC, 2005). Crude protein was determined by multiplying nitrogen (N) obtained from a Leco model FP-2000 N analyser (Leco Corp., St. Joseph, Michigan), according to the Dumas combustion method, using EDTA as a standard by a factor of 6.25 (AOAC, 2005). The EE was assessed by using diethyl ether as an extraction fluid in a Soxhlet apparatus (AOAC, 2005). The aNDFom and ADFom were analysed with a fibre analyser (FIWE6, VELP, Italy) using reagents described by Van Soest et al. (1991). Sodium sulphite and heat-stable $\alpha$-amylase were used in determining the aNDFom. After the dry ashing process of a homogenized sample at $550{ }^{\circ} \mathrm{C}$, Ca and $\mathrm{P}$ were determined by atomic absorption spectrophotometry using a Unicam UV 6-420 Supersipper spectrophotometer (GBC932AA, GBC Scientific Equipment Pty Ltd, Dandenong, Victoria, Australia), after wet digestion with nitric and perchloric acids (AOAC, 2005).

The experimental procedures were approved by and conformed to the requirements of the Animal Care and Use Committee of Southwest University in Chongqing City, southwestern China. Twenty-two yearold adult Dazu black wether goats (a local breed in southwest China, whose mature size is about $25 \mathrm{~kg}$ bodyweight), with an initial weight of $25.2 \pm 1.2 \mathrm{~kg}$ were used for this experiment. All wethers were kept individually in stainless steel metabolism cages in a temperature-controlled (at $21{ }^{\circ} \mathrm{C}$ ) and constantly lit animal house with free access to fresh water. Each wether was surgically fitted with a plastic ruminal cannula (4 cm internal diameter). About 60 days were allowed for the animals to recover from surgery. Before commencement of the experiment, all wethers were dewormed with Ivermectin by subcutaneous injection at a dosage of $0.2 \mathrm{mg}$ per $\mathrm{kg}$ bodyweight. These conditions were set to minimize possible effects of the animal on various parameters measured in the present experiment.

The basal diet (Table 1) was formulated according to MOA (2004) and NRC (2007). Rice straw from late-season rice (a local variety) obtained in the country of Chongqing City, southwestern China, was harvested, air dried and chopped manually to $1 \mathrm{~cm}$. The concentrate was coarsely ground through a 2.5-mm screen and $1 \mathrm{~kg}$ samples of rice straw and concentrate were randomly taken and finely ground through a 1 $\mathrm{mm}$ screen to analyse DM, GE, OM, CP, aNDFom, ADFom, EE, Ca and P (Table 1). The basal diet, consisting of $50 \%$ rice straw and $50 \%$ concentrate, was offered in equal amounts at 07:00 and 19:00. The total amount of basal diet offered to each wether was restricted to $850 \mathrm{~g} / \mathrm{kg}$ of its ad libitum intake (600 $\mathrm{g}$ per day per head, based on air-dried matter) to ensure that there was no refusal during the whole experimental period. The wethers were assigned equally to one of two dietary treatments according to a randomized 
controlled trial design with one study period of 38 days. The first 15 days of the experimental period were used for adaptation to diet and the following 23 to collect samples. Ten wethers from the control dietary treatment received the basal diet only. Ten wethers from the CHM mixture dietary treatment were offered the basal diet with the addition of the CHM mixture. The available amount of CHM mixture was $9 \mathrm{~g}$ per day per head on an air-dried basis, which is equivalent to an addition of $15 \mathrm{~g} / \mathrm{kg}$ to the basal diet. The supplemented $\mathrm{CHM}$ mixture was mixed evenly with the basal diet at each feeding.

Table 1 Chemical compositions ${ }^{1}(\mathrm{~g} / \mathrm{kg})$ of Chinese herbal mixture, ${ }^{2}$ rice straw, concentrate and basal diet

\begin{tabular}{|c|c|c|c|c|}
\hline & CHM mixture $^{2}$ & Rice straw & Concentrate $^{3}$ & Basal diet ${ }^{4}$ \\
\hline Dry matter & 890.5 & 887.6 & 873.2 & 880.4 \\
\hline Gross energy (MJ/kg) & 21.6 & 17.3 & 22.6 & 19.9 \\
\hline Organic matter & 893.3 & 809.1 & 900.2 & 854.6 \\
\hline Crude protein & 81.5 & 38.3 & 193.8 & 116.0 \\
\hline aNDFom & 536.2 & 677.7 & 262.0 & 469.9 \\
\hline ADFom & 385.1 & 506.9 & 162.4 & 334.6 \\
\hline Ether extract & 37.5 & 12.0 & 39.0 & 25.5 \\
\hline Calcium & 17.2 & 6.5 & 10.2 & 8.4 \\
\hline Phosphorus & 9.3 & 8.3 & 55.3 & 31.8 \\
\hline
\end{tabular}

\footnotetext{
${ }^{1}$ All values are expressed on a dry matter basis, except dry matter on an air-dried matter basis.

${ }^{2}$ CHM mixture: Chinese herb medicine mixture comprising Chinese Mosla, Atractylodes rhizome, Officinal Magnolia bark, white hyacinth bean and Liriope tuber with the weight ratio of 8:4:4:4:5.

${ }^{3}$ Concentrate was a mixture of $520 \mathrm{~g}$ corn, $120 \mathrm{~g}$ wheat bran, $240 \mathrm{~g}$ soybean meal, $70 \mathrm{~g}$ rapeseed meal, $20 \mathrm{~g}$ calcium carbonate, $10 \mathrm{~g}$ sodium chloride and $20 \mathrm{~g}$ vitamin and trace mineral premix per $\mathrm{kg}$ of dry matter. Vitamin and trace mineral premix contained per kg of dry matter: $119 \mathrm{~g} \mathrm{MgSO}_{4} \cdot \mathrm{H}_{2} \mathrm{O} ; 2.5 \mathrm{~g} \mathrm{FeSO} \cdot 7 \mathrm{H}_{2} \mathrm{O} ; 0.8 \mathrm{~g} \mathrm{CuSO} \cdot 5 \mathrm{H}_{2} \mathrm{O} ; 3 \mathrm{~g}$ $\mathrm{MnSO}_{4} \cdot \mathrm{H}_{2} \mathrm{O} ; 5 \mathrm{~g} \mathrm{ZnSO}_{4} \cdot \mathrm{H}_{2} \mathrm{O} ; 10 \mathrm{mg} \mathrm{Na}_{2} \mathrm{SeO}_{3} ; 40 \mathrm{mg} \mathrm{Kl} ; 30 \mathrm{mg} \mathrm{CoCl} 2 \cdot 6 \mathrm{H}_{2} \mathrm{O} ; 95000$ IU vitamin A; 17500 IU vitamin D and $18000 \mathrm{IU}$ vitamin $\mathrm{E}$.

${ }^{4}$ All values were calculated based on the basal diet, which consisted of $500 \mathrm{~g} / \mathrm{kg}$ rice straw and $500 \mathrm{~g} / \mathrm{kg}$ concentrate. aNDFom: amylase-treated ash-free neutral detergent fibre.

ADFom: ash-free acid detergent fibre.
}

Rumen degradability of concentrate and rice straw were determined using the in situ nylon bag technique from day 16 to day 17 and from day 20 to day 22, respectively. On day 25, ruminal fluid was collected via the cannulae to estimate rumen fermentation characteristics. On day 28 , ruminal digesta were obtained via the cannulae to measure the activities of fibrolytic enzymes. From day 31 to day 36 , all faeces were collected and sampled for evaluation of apparent digestibility of nutrients in the total tract. On day 38 , blood samples were collected from the jugular vein or auricular artery to analyse blood profiles. The time in which samples were not being collected, permitted wethers to adjust their physical condition.

The procedure for incubating nylon bags in the rumen of animals was modified slightly according to Vanzant et al. (1998). Nylon bags $(10 \mathrm{~cm} \times 7 \mathrm{~cm}, 35 \mu \mathrm{m}$ pore size), which contained $5 \mathrm{~g}$ concentrate or $3 \mathrm{~g}$ rice straw, ground to pass through a 4-mm screen, were incubated in duplicate in the rumen of all wethers for $0,2,4,8,12,24,36$ and $48 \mathrm{~h}$ and $0,2,4,6,12,24,48$ and $72 \mathrm{~h}$, respectively. The $0 \mathrm{~h}$ time point represented non-incubated bags, which were treated similarly to the other bags on removal from the rumen. All bags were put into the rumen at the same time, and removed at the required intervals. When taken out of the rumen, the bags were washed gently by hand until the outflow of water became clear and odourless, and were stored at $-20^{\circ} \mathrm{C}$. At the end of collection period, the bags were thawed and washed together with the $0 \mathrm{~h}$ bags in a washing machine for $40 \mathrm{~min}$, and then dried at $65^{\circ} \mathrm{C}$ for $24 \mathrm{~h}$. All residues in the bags were removed carefully and finely milled through a $1 \mathrm{~mm}$ screen to analyse DM, OM, CP, aNDFom and ADFom. The rate and extent of degradation of the nutrients from rice straw and concentrate, such as DM, OM, CP, aNDFom and ADFom, were estimated with the exponential model of Ørskov \& McDonald (1979). Ruminal degradability of nutrients was calculated according to the following equations:

$$
d_{p}=a+b\left(l-e^{-k d(t)}\right) \text { and } E D=a+\left(b \times k_{d}\right) /\left(k_{d}+k_{p}\right),
$$


where $d_{p}$ was the potential disappearance rate at time $t(\%)$

$a$ was the soluble and very rapidly degradable fraction (\%)

$b$ was the insoluble but potentially degradable fraction (\%)

$k_{d}$ was the constant rate of degradation of fraction $b$ per hour $(\% / h)$

$t$ was the retention time in the rumen

$E D$ was the rumen effective degradability $k p$ was the outflow rate of ruminal digesta.

In the present study, $k_{p}$ was set as $4.08 \% / \mathrm{h}$ according to a previous study in which chromic oxide as the indigestibility marker was administered via the rumen cannulae (Wang et al., 2010). Importantly, the two studies used the same dietary ingredients and wethers of the same breed as well as similar age and bodyweight.

At $0.5,1,2,3,4,6,8,10$ and $12 \mathrm{~h}$ after the morning feeding, about $20 \mathrm{~mL}$ of ruminal fluid was obtained from several sites in the rumen (reticulum, dorsal and ventral sac) with a filter probe tube. The $\mathrm{pH}$ was measured immediately using an electric $\mathrm{pH}$ meter (Sartorius Basic $\mathrm{pH}$ Meter PB-20, Sartorius AG, Goettingen, Germany). Then samples were immediately squeezed through four layers of cheesecloth with a mesh size of $250 \mu \mathrm{m}$. A total of $8 \mathrm{~mL}$ filtrate was centrifuged (Himac CR22G2 centrifuge, Hitachi Koki Co. Ltd., Tokyo, Japan) at $20000 \times \mathrm{g}$ for $15 \mathrm{~min}$ at $4{ }^{\circ} \mathrm{C}$. Then, $1 \mathrm{~mL}$ of $20 \mathrm{~g} / \mathrm{L}$ sulphuric acid was added to $5 \mathrm{~mL}$ of the clear supernatant and stored at $-20^{\circ} \mathrm{C}$ to determine ammonia $\mathrm{N}$ by a phenol-hypochlorite assay (Chaney \& Marbach, 1962). Another $8 \mathrm{~mL}$ of filtrate was centrifuged at $500 \times \mathrm{g}$ for $10 \mathrm{~min}$ at $4{ }^{\circ} \mathrm{C}$. Five $\mathrm{mL}$ of the clear supernatant was put into a plastic bottle containing $1 \mathrm{~mL}$ of $250 \mathrm{~g} / \mathrm{L}$ meta-phosphoric acid and $1 \mathrm{~mL}$ of $6 \mathrm{~g} / \mathrm{L}$ 2-ethyl butyric acid (internal standard), and further centrifuged at $20000 \times g$ for 15 min at $4{ }^{\circ} \mathrm{C}$ to obtain a final supernatant, which was stored at $-20^{\circ} \mathrm{C}$ for the assay of individual and total volatile fatty acids (VFA) by gas chromatography (HP 5890, Hewlett Packard, USA) in accordance with the procedure described by Jouany (1982).

At $0.5,2,4,6,8,10$ and $12 \mathrm{~h}$ after the morning feeding, about $20 \mathrm{~g}$ of rumen digesta were collected from several sites in the rumen (reticulum, dorsal and ventral sac) with long-handle forceps, and immediately placed in an ice bath to stop microbial fermentation quickly. After being weighed accurately, samples were mixed equally with ice-cold phosphate buffer solution ( $50 \mathrm{mM} ; \mathrm{pH}=6.0)$ according to the weight ratio of $1: 1$, and strained directly through four layers of cheesecloth. The filtered fluid was centrifuged at $800 \times g$ for 15 min at $4{ }^{\circ} \mathrm{C}$ to acquire the supernatant fraction without small digesta particles. Then $20 \mathrm{~mL}$ of this clear supernatant was subjected to sonication by a biologics ultrasonic homogenizer (BJED-20950, Beijing Yongda Ultrasonic Co. Ltd., Beijing, China) at $4^{\circ} \mathrm{C}$ (ice waterbath, $30 \mathrm{~s}$ pulse rate) for $10 \mathrm{~min}$, and further centrifuged at $27000 \times g$ for $20 \mathrm{~min}$ at $4^{\circ} \mathrm{C}$ to obtain an ultimate supernatant as a source of microbial enzymes, which was subsequently stored at $-20^{\circ} \mathrm{C}$ until analyses. Enzyme activities were evaluated by determining reducing sugar formation from $0.5 \%$ sodium carboxymethyl cellulose (i.e. $0.5 \mathrm{~g}$ sodium carboxymethyl cellulose in 100 $\mathrm{mL}$ of $0.2 \mathrm{M}$ phosphate buffer solution) for carboxymethyl cellulase (CMCase) activity (Manyuchi et al., 1992), from $0.5 \%$ avicel microcrystalline cellulose (i.e. $0.5 \mathrm{~g}$ avicel microcrystalline cellulose in $100 \mathrm{~mL}$ of $0.2 \mathrm{M}$ phosphate buffer solution) for avicelase (Wood \& Bhat, 1988), from $0.5 \%$ salicin (i.e. $0.5 \mathrm{~g}$ salicin in $100 \mathrm{~mL}$ of $0.2 \mathrm{M}$ phosphate buffer solution) for cellobiase (Agarwal et al., 2000) and from 0.5\% xylan (i.e. $0.5 \mathrm{~g}$ xylan in $100 \mathrm{~mL}$ of $0.2 \mathrm{M}$ phosphate buffer solution) for xylanase (Lowe et al., 1987), respectively. The enzyme reactions were initiated by the successive addition of $1 \mathrm{~mL}$ preheated substrate and $0.2 \mathrm{~mL}$ enzyme solution, and then incubated at $39^{\circ} \mathrm{C}$ for 60 minutes. After adding $2 \mathrm{~mL} 3,5$-dinitrosalicylic acid (DNS reagent), the reactions were terminated by heating in a boiling waterbath for 10 minutes (Miller, 1959). The colour that formed, was read at $550 \mathrm{~nm}$ by a Shimadzu UV-2450 spectrophotometer (Japan). D-glucose was used as standard for CMCase, avicelase and cellobiase, and D-xylose for xylanase, respectively. One international unit (IU) was equivalent to the enzyme activity releasing $1 \mu \mathrm{mol}$ glucose or xylose per minute per mL enzyme solution.

Total faecal output per day for each wether was collected in a faecal collection bag and weighed accurately. The amount of $100 \mathrm{~g} / \mathrm{kg}$ daily faecal output was sampled, and mixed uniformly with $10 \mathrm{~mL} 100$ $\mathrm{mg} / \mathrm{g}$ sulphuric acid, then stored at $-20^{\circ} \mathrm{C}$. At the end of experiment, all representative samples were composited for each wether and across days, and dried at $65^{\circ} \mathrm{C}$ for $72 \mathrm{~h}$. Dried samples were weighed, and ground through a 1-mm screen, then analysed for DM, GE, OM, CP, aNDFom, ADFom, EE, Ca and P. For the apparent digestibility of wethers fed $\mathrm{CHM}$ mixture, the nutrients provided by the mixture were regarded as part of nutrient intake because of their availability in the digestive tract.

At $1,3,6,9$ and $12 \mathrm{~h}$ after the morning feeding, blood samples from each wether were collected by methods based on diverse required parameters. Thus, $2 \mathrm{~mL}$ blood was pumped from the auricular artery with a heparinized syringe. The syringe was chilled immediately in an ice bath. The blood gas parameters, including $\mathrm{pH}$, the concentrations of total carbon dioxide $\left(\mathrm{CO}_{2}\right)$, actual bicarbonate and buffer excess, the partial pressure of $\mathrm{CO}_{2}$ and oxygen $\left(\mathrm{O}_{2}\right)$, percent $\mathrm{O}_{2}$ saturation, ion concentration of calcium as $\mathrm{Ca}^{2+}$, 
phosphorus as $\mathrm{P}^{5-}$ and magnesium as $\mathrm{Mg}^{2+}$, were recorded in 15 minutes by a blood gas and electrolyte analyser (Osmetech OPTI ${ }^{\text {TM }}$ CCA, Osmetech Medical Systems Inc., Roswell, USA). The amount of $12 \mathrm{~mL}$ blood was collected from the jugular vein and placed in aseptic vacutainer tubes containing heparin sodium. The tubes were gently inverted a couple of times, then kept in an icebox and later centrifuged at $4{ }^{\circ} \mathrm{C}, 2500 \mathrm{~g}$ for 15 minutes to harvest plasma. The aliquots of plasma were transferred into storage tubes labelled with date and animal identification, then stored at $-20^{\circ} \mathrm{C}$ until further analysis. Three assay methods were employed for the plasma parameters. The first involved the use of an automatic gamma counter (CliniGamma 1272-001, LKB-WALLAC, Finland). The levels of hormones, namely growth hormone (GH), insulin, glucagon, leptin, adrenocorticotropic hormone (ACTH), aldosterone, cortisol, thyroid-stimulating hormone (TSH), triiodothyronine $\left(T_{3}\right)$, tetraiodothyronine $\left(T_{4}\right)$ and interleukin-2, were carried out by radioimmunoassay, while the required commercial kits were purchased from Beijing North Institute of Biological Techbology (Beijing, China). The second assay method involved the use of an automatic biochemistry analyser (Synchron CX5 Pro, Beckman Coulter, Fullerton, Calif, USA). The concentrations of metabolites - including glucose, urea $\mathrm{N}$, uric acid, creatinine, triglyceride, total cholesterol, low-density lipoprotein cholesterol (LDLC), high-density lipoprotein cholesterol (HDLC), lactic acid, total protein, albumin, C-reactive protein (CRP), immunoglobulin (Ig) A/G/M, complement $3 / 4$, as well as the activities of enzymes encompassing aspartate transaminase (AST, EC 2.6.1.1), alanine transaminase (ALT, EC 2.6.1.2), lactate dehydrogenase (LDH, EC 1.1.1.27), creatine kinase (CK, EC 2.7.3.2), alkaline phosphatase (EC 3.1.3.1) and a-amylase (EC 3.2.1.1) - were measured with commercial kits from Beckman Coulter. The third method involved the use of a spectrophotometer (Thermo Scientific BioMate 3S, Thermo Fisher Scientific Inc, Shanghai, China). The concentrations of nitric oxide (NO) and maleic dialdehyde (MDA), the activities of nitric oxide synthase (NOS, EC 1.14.13.39), catalase (EC 1.11.1.6), glutathione peroxidase (GSH-Px, EC 1.11.1.9), total superoxide dismutase (SOD, EC 1.15.1.1) and total antioxidative capacity (AOC) as well as the inhibition capacity of hydroxyl free radical $(-\mathrm{OH})$ were detected by hand with commercial kits from Nanjing Jiancheng Bioengineering Research Institute (Nanjing, China) according to the manufacturers' instructions and protocols of the kits.

Table 2 Effects of Chinese herbal mixture ${ }^{1}$ on fermentation parameters and fibrolytic enzymes (average of all sampling times) in the rumen of goats

\begin{tabular}{|c|c|c|c|c|}
\hline Items & Control & CHM mixture ${ }^{1}$ & SEM $^{2}$ & $P$-value \\
\hline $\mathrm{pH}$ & $6.45 \pm 0.22$ & $6.47 \pm 0.16$ & 0.02 & 0.77 \\
\hline Ammonia nitrogen (mg/dL) & $19.09 \pm 5.49$ & $18.89 \pm 5.80$ & 0.66 & 0.88 \\
\hline \multicolumn{5}{|l|}{ Volatile fatty acid, $\mathrm{mmol} / \mathrm{L}$} \\
\hline Acetate & $34.46 \pm 3.71$ & $36.48 \pm 4.32$ & 0.48 & 0.04 \\
\hline Propionate & $13.43 \pm 2.06$ & $13.79 \pm 2.24$ & 0.25 & 0.48 \\
\hline Butyrate & $6.83 \pm 1.18$ & $7.61 \pm 1.76$ & 0.18 & 0.03 \\
\hline Total & $54.72 \pm 6.49$ & $57.89 \pm 7.76$ & 0.85 & 0.07 \\
\hline \multicolumn{5}{|l|}{ Volatile fatty acid, mol/100 mol } \\
\hline Acetate & $63.07 \pm 1.94$ & $63.17 \pm 2.14$ & 0.23 & 0.84 \\
\hline Propionate & $24.49 \pm 1.70$ & $23.81 \pm 1.85$ & 0.21 & 0.11 \\
\hline Butyrate & $12.43 \pm 1.12$ & $13.01 \pm 1.85$ & 0.18 & 0.11 \\
\hline Acetate/propionate & $2.59 \pm 0.23$ & $2.67 \pm 0.27$ & 0.03 & 0.18 \\
\hline \multicolumn{5}{|l|}{ Fibrolytic enzymes activities, IU } \\
\hline Avicelase & $0.83 \pm 0.10$ & $0.91 \pm 0.06$ & 0.01 & 0.00 \\
\hline Carboxymethyl cellulase & $0.83 \pm 0.10$ & $0.92 \pm 0.08$ & 0.01 & 0.00 \\
\hline Cellobiase & $0.81 \pm 0.11$ & $0.89 \pm 0.06$ & 0.01 & 0.00 \\
\hline Xylanase & $0.94 \pm 0.12$ & $1.02 \pm 0.08$ & 0.01 & 0.00 \\
\hline
\end{tabular}

${ }^{1} \mathrm{CHM}$ mixture: Chinese herb medicine mixture comprising Chinese Mosla, Atractylodes rhizome, Officinal Magnolia bark, white hyacinth bean and Liriope root tuber with the weight ratio of 8:4:4:4:5.

${ }^{2}$ SEM: standard error of mean. 
Data were subject to a one-way analysis of variance using the PROC GLM procedure of SAS with dietary treatment as the classification factor (SAS, 2005). Data were summarized by sampling time and then analysed using the same mixed model, but with time included as a repeated measure using compound symmetry. Results were expressed as means \pm standard deviation $(\mathrm{M} \pm \mathrm{SD})$. Comparisons between average values for the CHM mixture group and the control group were conducted by Duncan's multiple range tests. Degree of significance was defined as $P>0.10$, no significance; $0.05<P<0.10$, tendency; $P<0.05$, significance.

\section{Results}

The effects of the CHM mixture on fermentation parameters and fibrolytic enzymes in the rumen are presented in Table 2 (above). The addition of the mixture increased the ruminal concentrations of acetate and butyrate, as well as the ruminal activities of avicelase, carboxymethyl cellulase, cellobiase and xylanase, and trended towards increased total VFA concentration in the rumen.

The effects of the $\mathrm{CHM}$ mixture on rumen effective degradability of nutrients from rice straw and concentrate are presented in Table 3. With the addition of $\mathrm{CHM}$ mixture, the rumen effective degradability of DM, OM and aNDFom from rice straw was increased, while that of ADFom from rice straw as well as the DM and ADFom from concentrate had a tendency to increase.

Table 3 Effects of Chinese herbal mixture mixture ${ }^{1}$ on rumen effective degradability (\%) of nutrients from rice straw and concentrate in goats

\begin{tabular}{lllll}
\hline Items & Control & CHM mixture $^{1}$ & SEM & $P$-val \\
\hline Rice straw & & & & \\
$\quad$ Dry matter & $26.11 \pm 1.58$ & $29.44 \pm 0.16$ & 0.73 & 0.01 \\
$\quad$ Organic matter & $35.69 \pm 0.89$ & $38.31 \pm 1.26$ & 0.61 & 0.02 \\
Crude protein & $20.68 \pm 0.65$ & $21.25 \pm 0.22$ & 0.19 & 0.14 \\
aNDFom & $25.53 \pm 0.56$ & $27.41 \pm 0.82$ & 0.42 & 0.01 \\
ADFom & $25.67 \pm 1.16$ & $28.69 \pm 2.24$ & 0.82 & 0.05 \\
Concentrate & & & & \\
$\quad$ Dry matter & $54.08 \pm 2.23$ & $57.85 \pm 2.98$ & 1.12 & 0.09 \\
Organic matter & $58.19 \pm 3.56$ & $58.29 \pm 3.18$ & 1.11 & 0.97 \\
Crude protein & $50.59 \pm 2.39$ & $48.88 \pm 1.85$ & 0.77 & 0.30 \\
aNDFom & $52.04 \pm 1.32$ & $54.19 \pm 1.77$ & 0.65 & 0.10 \\
ADFom & $51.28 \pm 2.59$ & $55.76 \pm 2.71$ & 1.21 & 0.05
\end{tabular}

${ }^{1}$ CHM mixture: Chinese herb medicine mixture comprising Chinese Mosla, Atractylodes rhizome, Officinal Magnolia bark, white hyacinth bean and Liriope root tuber with the weight ratio of 8:4:4:4:5.

SEM: standard error of mean.

aNDFom: amylase-treated ash-free neutral detergent fibre.

ADFom: ash-free acid detergent fibre.

The effects of the CHM mixture on apparent digestibility of nutrients in the total tract are presented in Table 4. The addition of the mixture increased the apparent digestibility of GE, DM, OM, CP, aNDFom, ADFom and $\mathrm{Ca}$, and had no significant effect on the apparent digestibility of $\mathrm{EE}$ in the total tract. The effects of the mixture on blood gas parameters are presented in Table 5. With the addition of the CHM mixture, $\mathrm{pH}$, concentrations of actual bicarbonate, buffer excess and $\mathrm{Mg}^{2+}$ were increased in the blood.

The effects of the CHM mixture on plasma parameters are presented in Tables $6 \mathrm{a}$ and $6 \mathrm{~b}$. For the plasma hormones, the CHM mixture increased the level of leptin and decreased the levels of ACTH, aldosterone and cortisol. In addition, the levels of $\mathrm{GH}$, insulin and $\mathrm{T}_{4}$ had an upward tendency. For plasma enzymes, the CHM mixture decreased the activities of ALT, CK and LDH. For the plasma immune parameters, the CHM mixture increased the concentrations of total protein, albumin, globulin, CRP, Ig A/G/M, complement $3 / 4$, as well as the activity of NOS. In addition, the concentration of NO had an upward tendency. For the plasma antioxidative parameters, CHM mixture increased the activities of GSH-Px and total SOD as well as total AOC. In addition, the activity of catalase had an upward tendency. For other plasma metabolites, 
the CHM mixture decreased the concentrations of glucose, urea $\mathrm{N}$ and lactic acid. In addition, the concentration of creatinine showed a downward tendency.

Table 4 Effects of Chinese herbal mixture mixture ${ }^{1}$ on apparent digestibility (\%) of nutrients in the total tract of goats

\begin{tabular}{lllll}
\hline Items & Control & CHM mixture $^{\mathbf{1}}$ & SEM & $\boldsymbol{P}^{\text {-value }}$ \\
\hline Gross energy & $72.21 \pm 1.22$ & $76.30 \pm 1.26$ & 0.87 & 0.00 \\
Dry matter & $65.94 \pm 0.90$ & $70.82 \pm 2.62$ & 1.12 & 0.01 \\
Organic matter & $70.40 \pm 1.02$ & $75.06 \pm 2.45$ & 1.07 & 0.01 \\
Crude protein & $71.45 \pm 1.64$ & $76.95 \pm 2.77$ & 1.28 & 0.01 \\
aNDFom & $58.73 \pm 2.02$ & $65.17 \pm 4.14$ & 1.62 & 0.03 \\
ADFom & $65.44 \pm 1.90$ & $70.44 \pm 1.88$ & 1.13 & 0.01 \\
Ether extract & $76.16 \pm 2.79$ & $83.59 \pm 5.55$ & 2.01 & 0.05 \\
Calcium & $18.02 \pm 2.94$ & $26.24 \pm 5.37$ & 2.10 & 0.04 \\
Phosphorus & $58.42 \pm 8.78$ & $61.44 \pm 6.72$ & 2.62 & 0.61 \\
\end{tabular}

\footnotetext{
${ }^{1} \mathrm{CHM}$ mixture: Chinese herb medicine mixture comprising Chinese Mosla, Atractylodes rhizome, Officinal Magnolia bark, white hyacinth bean and Liriope root tuber with the weight ratio of 8:4:4:4:5.

SEM: standard error of mean.

aNDFom: amylase-treated ash-free neutral detergent fibre.

ADFom: ash-free acid detergent fibre.
}

Table 5 Effects of Chinese herbal mixture mixture ${ }^{1}$ on blood gas parameters (average of all the sampling times) in goats

\begin{tabular}{lcccc}
\hline Items & Control & CHM $^{\text {mixture }} \mathbf{1}^{\mathbf{1}}$ & SEM $^{2}$ & $\boldsymbol{P}_{\text {-value }}$ \\
\hline $\mathrm{pH}$ & $7.36 \pm 0.03$ & $7.41 \pm 0.04$ & 0.01 & 0.00 \\
Total carbon dioxide (mmol/L) & $26.88 \pm 2.36$ & $28.81 \pm 4.05$ & 0.60 & 0.11 \\
Actual bicarbonate (mmol/L) & $21.83 \pm 1.82$ & $25.26 \pm 4.61$ & 0.68 & 0.01 \\
Buffer excess (mmol/L) & $2.06 \pm 2.11$ & $6.38 \pm 4.33$ & 0.77 & 0.00 \\
Carbon dioxide partial pressure (mm Hg) & $36.19 \pm 2.69$ & $37.07 \pm 3.22$ & 0.52 & 0.41 \\
Oxygen partial pressure (mm Hg) & $87.9 \pm 15.10$ & $91.9 \pm 19.30$ & 3.04 & 0.51 \\
Percent oxygen saturation (\%) & $95.4 \pm 2.85$ & $96.1 \pm 2.09$ & 0.44 & 0.44 \\
Calcium ion (mmol/L) & $1.27 \pm 0.39$ & $1.31 \pm 0.24$ & 0.05 & 0.73 \\
Phosphorus ion (mmol/L) & $2.88 \pm 0.35$ & $2.97 \pm 0.54$ & 0.08 & 0.55 \\
Magnesium ion (mmol/L) & $1.06 \pm 0.11$ & $1.19 \pm 0.18$ & 0.02 & 0.02 \\
& & & &
\end{tabular}

${ }^{1} \mathrm{CHM}$ mixture: Chinese herbal medicine mixture comprising Chinese Mosla, Atractylodes rhizome, Officinal Magnolia bark, white hyacinth bean and Liriope root tuber with the weight ratio of 8:4:4:4:5.

${ }^{2}$ SEM: standard error of mean.

\section{Discussion}

Nowadays, with the demand for 'clean, green and ethical' animal production, phytogenic substances such as plants, parts of plants, and secondary products of herbal origin have gained considerable attention in animal nutrition (Durmic \& Blache, 2012). CHM is classified as the category of natural plant product that produces a diverse array of secondary metabolites to provide protection against microbial and insect attacks (Hart et al., 2008). It is well documented that plants containing phytochemicals and that their extracts can manipulate the function of the gastrointestinal tract in both ruminant and non-ruminant livestock (Greathead, 2003; Wallace, 2004). Besides the effect on gut function, possible CHM modes of action include nutritional 
effects, immune function accentuation, antimicrobial action, anti-oxidation and anti-stress effect (Liu \& Xu, 2011; Liu et al., 2011; Lu, 2011).

Table 6a Effects of Chinese herbal mixture mixture ${ }^{1}$ on plasma parameters (average all the sampling times) in goats

\begin{tabular}{|c|c|c|c|c|}
\hline Items & Control & CHM mixture ${ }^{1}$ & SEM & $P$-value \\
\hline \multicolumn{5}{|l|}{ Hormone levels } \\
\hline Growth hormone (ng/mL) & $0.34 \pm 0.17$ & $0.86 \pm 0.35$ & 0.15 & 0.08 \\
\hline Insulin $(\mu \mathrm{lU} / \mathrm{mL})$ & $12.17 \pm 5.94$ & $18.67 \pm 7.59$ & 1.91 & 0.09 \\
\hline Glucagon (pg/mL) & $141.6 \pm 22.0$ & $136.0 \pm 20.7$ & 3.8 & 0.47 \\
\hline Leptin (ng/mL) & $1.04 \pm 0.34$ & $1.47 \pm 0.54$ & 0.09 & 0.01 \\
\hline ACTH $(p g / m L)$ & $22.00 \pm 7.53$ & $16.31 \pm 7.54$ & 1.41 & 0.04 \\
\hline Aldosterone (ng/mL) & $0.08 \pm 0.03$ & $0.05 \pm 0.03$ & 0.01 & 0.04 \\
\hline Cortisol (ng/mL) & $26.00 \pm 3.96$ & $19.61 \pm 5.42$ & 1.01 & 0.00 \\
\hline $\mathrm{TSH}^{4}(\mu \mathrm{IU} / \mathrm{mL})$ & $0.21 \pm 0.09$ & $0.28 \pm 0.14$ & 0.02 & 0.11 \\
\hline Triiodothyronine (ng/mL) & $4.15 \pm 2.75$ & $4.93 \pm 2.79$ & 0.49 & 0.43 \\
\hline Tetraiodothyronine (ng/mL) & $326.6 \pm 5.8$ & $330.4 \pm 5.2$ & 1.0 & 0.06 \\
\hline \multicolumn{5}{|l|}{ Enzymatic activities } \\
\hline ALT (U/L) & $20.19 \pm 5.76$ & $14.56 \pm 4.22$ & 1.01 & 0.00 \\
\hline AST (U/L) & $43.12 \pm 14.53$ & $40.50 \pm 8.09$ & 1.02 & 0.11 \\
\hline Creatine kinase (U/L) & $150.3 \pm 46.6$ & $118.5 \pm 35.4$ & 7.7 & 0.04 \\
\hline Alkaline phosphatase (U/L) & $185.4 \pm 53.5$ & $194.1 \pm 80.2$ & 15.1 & 0.78 \\
\hline Lactate dehydrogenase (U/L) & $445.6 \pm 98.0$ & $269.1 \pm 53.8$ & 40.5 & 0.03 \\
\hline a-amylase (U/L) & $45.38 \pm 16.94$ & $54.25 \pm 25.05$ & 3.80 & 0.25 \\
\hline \multicolumn{5}{|l|}{ Immune parameters } \\
\hline Total protein (g/L) & $74.11 \pm 3.98$ & $80.46 \pm 6.30$ & 1.07 & 0.00 \\
\hline Albumin $(g / L)$ & $34.49 \pm 1.70$ & $36.09 \pm 1.28$ & 0.29 & 0.01 \\
\hline Globulin (g/L) & $39.61 \pm 4.39$ & $44.37 \pm 6.78$ & 1.08 & 0.03 \\
\hline Albumin/globulin & $0.88 \pm 0.11$ & $0.83 \pm 0.14$ & 0.02 & 0.30 \\
\hline C-reactive protein (mg/dL) & $2.15 \pm 0.09$ & $2.47 \pm 0.35$ & 0.05 & 0.00 \\
\hline Immunoglobulin A (g/L) & $1.21 \pm 0.03$ & $2.44 \pm 0.41$ & 0.12 & 0.00 \\
\hline Immunoglobulin G (g/L) & $9.07 \pm 0.64$ & $10.42 \pm 0.83$ & 0.17 & 0.00 \\
\hline Immunoglobulin M (g/L) & $8.71 \pm 1.26$ & $10.36 \pm 1.68$ & 0.29 & 0.00 \\
\hline Complement 3 (g/L) & $0.25 \pm 0.03$ & $0.38 \pm 0.03$ & 0.01 & 0.00 \\
\hline Complement 4 (g/L) & $0.40 \pm 0.04$ & $0.68 \pm 0.04$ & 0.02 & 0.00 \\
\hline Interleukin-2 (ng/mL) & $4.88 \pm 1.34$ & $6.14 \pm 3.63$ & 0.49 & 0.20 \\
\hline Nitric oxide $(\mu \mathrm{mol} / \mathrm{L})$ & $35.86 \pm 15.74$ & $47.73 \pm 17.09$ & 3.05 & 0.05 \\
\hline Nitric oxide synthase (U/mL) & $12.09 \pm 1.11$ & $13.04 \pm 1.38$ & 0.23 & 0.04 \\
\hline
\end{tabular}

${ }^{1}$ CHM mixture: Chinese herb medicine mixture comprising Chinese Mosla, Atractylodes rhizome, Officinal Magnolia bark, white hyacinth bean and Liriope root tuber with the weight ratio of 8:4:4:4:5.

SEM: standard error of mean.

ACTH: adrenocorticotropic hormone; TSH: thyroid-stimulating hormone; ALT: alanine transaminase;

AST: aspartate transaminase. 
Table $6 \mathrm{~b}$ Effects of Chinese herbal mixture mixture ${ }^{1}$ on plasma parameters (average of all the sampling times) in goats

\begin{tabular}{|c|c|c|c|c|}
\hline Items & Control & CHM mixture $^{1}$ & SEM $^{2}$ & $P$-value \\
\hline \multicolumn{5}{|l|}{ Antioxidative parameters } \\
\hline Maleic dialdehyde (nmol/mL) & $10.04 \pm 3.95$ & $8.75 \pm 2.39$ & 0.58 & 0.27 \\
\hline Total antioxidative capacity (U/mL) & $1.86 \pm 0.43$ & $2.87 \pm 1.83$ & 0.25 & 0.04 \\
\hline Catalase (U/mL) & $4.19 \pm 3.55$ & $6.34 \pm 3.48$ & 0.64 & 0.09 \\
\hline Glutathione peroxidase $(\mu \mathrm{mol} / \mathrm{L})$ & $133.7 \pm 38.1$ & $177.5 \pm 54.5$ & 9.1 & 0.01 \\
\hline Total superoxide dismutase (U/mL) & $75.67 \pm 13.02$ & $86.41 \pm 11.16$ & 2.32 & 0.02 \\
\hline$-\mathrm{OH}(\mathrm{U} / \mathrm{mL})$ & $597.8 \pm 206.4$ & $676.3 \pm 192.7$ & 35.4 & 0.28 \\
\hline \multicolumn{5}{|l|}{ Other metabolites } \\
\hline Glucose (mmol/L) & $3.83 \pm 1.51$ & $2.90 \pm 0.38$ & 0.21 & 0.02 \\
\hline Urea nitrogen (mmol/L) & $6.05 \pm 0.63$ & $5.31 \pm 1.05$ & 0.16 & 0.03 \\
\hline Uric acid (mmol/L) & $175.0 \pm 63.2$ & $158.8 \pm 54.4$ & 10.4 & 0.44 \\
\hline Creatinine $(\mu \mathrm{mol} / \mathrm{L})$ & $81.94 \pm 9.75$ & $75.75 \pm 9.01$ & 1.72 & 0.07 \\
\hline Triglyceride (mmol/L) & $0.19 \pm 0.04$ & $0.17 \pm 0.04$ & 0.00 & 0.25 \\
\hline Total cholesterol (mmol/L) & $2.38 \pm 0.21$ & $2.22 \pm 0.78$ & 0.10 & 0.44 \\
\hline LDLC (mmol/L) & $0.63 \pm 0.28$ & $0.58 \pm 0.22$ & 0.04 & 0.57 \\
\hline HDLC (mmol/L) & $1.55 \pm 0.21$ & $1.48 \pm 0.46$ & 0.06 & 0.62 \\
\hline Lactic acid (mmol/L) & $2.19 \pm 1.04$ & $1.56 \pm 0.51$ & 0.15 & 0.04 \\
\hline
\end{tabular}

${ }^{1}$ CHM mixture: Chinese herb medicine mixture comprising Chinese Mosla, Atractylodes rhizome, Officinal Magnolia bark, white hyacinth bean and Liriope root tuber with the weight ratio of 8:4:4:4:5.

SEM: standard error of the mean.

$-\mathrm{OH}$ : inhibition capacity of hydroxyl free radical:

LDLC: low-density lipoprotein cholesterol:

HDLC: high-density lipoprotein cholesterol.

In general, the bioactive botanical substances in CHM could be divided structurally into terpenes or isoprenoids, phenols and alkaloids. Four major types with potential use in ruminant nutrition are saponins, tannins, organosulphur compounds and essential oils (Bodas et al., 2012). In the present study, the CHM mixture was composed of Chinese Mosla, Atractylodes lancea, Officinal Magnolia bark, white hyacinth bean and Liriope root tuber. According to Chinese medical principles, in this mixture, Chinese Mosla serves as the principal medicine, and Atractylodes lancea and Officinal Magnolia bark represent the associate medicines, while white hyacinth bean and Liriope root tuber act as the adjuvant and messenger medicine, respectively. The action of this mixture may be related to the combined functions of individual medicines. At present, the pharmacological effects of every herb, together with its main effective components, have been interpreted in detail by China Pharmacopeia, an authoritative book from the Chinese Government (ChPC, 2010). However, the chemical nature of each active compound still needs to be specified. Chinese Mosla, a kind of heatclearing and summerheat-relieving drug, consists mainly of elscholtzione and sesquiterpene (ChPC, 2010). Atractylodes lancea, which is responsible for eliminating dampness, generally includes atractylol, atractylone, carotene and vitamin $\mathrm{B}_{1}(\mathrm{ChPC}, 2010)$. The herb medicine, Officinal Magnolia bark, regulates the flow of vital energy and removing obstruction to it, embodies largely magnolol, tetrahydromagnolol, $\beta$-eucalyptus phenol and magnocurarine (ChPC, 2010). White hyacinth bean is a drug for dispelling internal cold, and comprises mostly protein, vitamin $B_{1}$, vitamin $C$, carotene, saccharose and phytotoxin (ChPC, 2010). Liriope root tuber, being the agent of tonification of deficiency and nourishment for vitality, mostly includes mucoid substances, glucose, vitamin A and $\beta$-sitosterol (ChPC, 2010). As a result, their mixture may contain plenty of blends of essential oils, along with nutrients. Because the concentrations of secondary compounds in each raw plant material (above) might be low, a considerable amount of their mixture (15 mg CHM mixture per $\mathrm{g}$ of basal diet) was added to supply adequate amounts of active compounds. In addition, from the point of chemical composition, the nutritional value of this mixture was superior to that of rice straw, suggesting that the mixture might provide extra available nutrients to the goats.

The effects of essential oils on rumen fermentation have been well reviewed (Hart et al., 2008; Patra \& 
Saxena, 2010). Ruminal pH and VFA profile have been closely associated with dietary ingredients and chemical compositions (Mertens, 1997). Diets rich in non-structural carbohydrates such as starch tend to decrease ruminal $\mathrm{pH}$ and stimulate propionate production, while those rich in structural carbohydrates such as NDF tend to increase ruminal $\mathrm{pH}$ and prompt the formation of acetate and butyrate. In the present study, since $50 \%$ of the basal diet was dried rice straw, which is categorized as low-quality roughage, the $\mathrm{pH}$ and acetate concentration in the rumen of all of the goats were relatively high. $\mathrm{A}$ higher $\mathrm{pH}$ in the rumen is beneficial to the growth of ruminal microbes responsible for breaking down plant fibres (Russell \& Wilson, 1996). Thus, $\mathrm{pH}$ in the rumen of the goats was within optimum ranges for cellulolytic microbes involving major cellulolytic bacterial populations and highly fibrolytic anaerobic fungi, and would not be a limiting factor to acetate production (Pitt et al., 1996). In the present study, the CHM mixture could markedly enhance the activities of fibre-degrading enzymes, implying that the mixture might improve rumen fibre degradation and so enhance the production of acetate and butyrate. Castillejos et al. $(2005 ; 2007)$ reported a similar effect on individual VFA production, using $5 \mathrm{mg}$ blend of essential oils (BEO) per d, measured as a daily composite sample, in continuous fermenters, suggesting that essential oil supplementation might selectively stimulate acetate formation. However, the CHM mixture could not affect the acetate to propionate ratio and the proportions of individual VFAs in spite of an upward tendency in total VFA production, showing no change in the type of rumen fermentation. The effects of essential oils on ruminal VFA production depend on rumen $\mathrm{pH}$ (Cardozo et al., 2005; Spanghero et al., 2008). At a high rumen pH, there could be minor changes in rumen VFA production, since essential oil feeding would happen because the dissociated hydrophobic form of active molecules of essential oil is less vigorous against the cell membrane of rumen microbes.

The promotion of fibre degradation in the rumen with the dietary supplementation of CHM mixture could be verified by the in situ ruminal degradability of fibrous matter from dietary forage and concentrate. However, the CHM mixture showed a significant influence on the degradation of fibre from dietary forage. Most rumen microbes responsible for final fibre degradability inhabit the solid phase of ruminal digesta, which consists of the insoluble and slowly degradable fraction of feedstuffs such as fibre (Miron et al., 2001). Maybe the CHM mixture exerted preferential impacts on the particle-bound microbes in the rumen. In other words, the rumen microorganisms surviving in the liquid phase of digesta suffered little suppression from the $\mathrm{CHM}$ mixture, which was why no distinct difference was observed in the rumen effective degradability of $\mathrm{CP}$ from dietary forage or concentrate with addition of the CHM mixture. Mclntosh et al. (2003) and Newbold et al. (2004) reported no effects of BEO on proteolytic and deaminative activity in the rumen of both sheep and cattle. Hart et al. (2008) noted that one action of BEO was to modify microbial attachment and colonization of plant material entering the rumen, which was more likely to affect the breakdown of insoluble as opposed to soluble protein sources. In addition, the slight difference in ruminal production of ammonia- $\mathrm{N}$ with the dietary supplementation of $\mathrm{CHM}$ mixture indirectly suggests a limited effect of the mixture on the rumen metabolism of dietary CP fraction. The marked improvement in the apparent whole tract digestibility of NDF and ADF might be owing to the positive influence of the CHM mixture on the rumen degradation of ingested fibre since it is always difficult for the fibrous components of feedstuffs to be digested in the hindgut of animals (Montagne et al., 2003). Benchaar et al. (2006) found that NDF and ADF digestibility were increased by the addition of a mixture of essential oils, and indicated that they could stimulate cellulosedegrading bacteria. However, the prominently higher apparent digestibility of $\mathrm{CP}$, EE and $\mathrm{Ca}$ in the total tract with the addition of $\mathrm{CHM}$ mixture hinted that part of the $\mathrm{CHM}$ mixture entering the rumen might escape the capture of ruminal microbes, and flow into the intestinal tract of goats, later exerting a beneficial influence on the hindgut digestion of nutrients. Overall, the CHM mixture had advantageous modulation effects on the digestive physiology of goats, thus improving the utilization of nutrients, together with the efficiency of ingested GE.

Blood gas, being closely interrelated with the acid-base components and the electrolytes in the blood, is a key factor in the maintenance of internal homeostasis in the body (Baillie, 2008). Consequently, clinical analysis of blood gas is a comprehensive diagnosis including the gas, the acid-base balance and the electrolyte metabolism in the blood. Based on the results of blood gas analysis in the present study, the CHM mixture promoted the blood buffer capacity, as well as the acid-base equilibrium, but negligibly served the exchange and transport of blood gas.

Hormones are a class of regulatory biochemicals that are produced in all multicellular organisms by glands, and transported by the circulatory system to a distant target organ to coordinate its physiology and behaviour (Prosser, 1991). Hormones regulate a variety of physiological and behavioural activities. The effects of growth hormone (GH) on the tissues of body can generally be described as anabolic. The GH, which is synthesized, stored and secreted by the somatotroph cells within the lateral wings of anterior pituitary gland in the brain, stimulates growth, cell reproduction and regeneration, as well as the production of insulin-like growth factor 1 in animals (Liu et al., 2007). The CHM mixture tended to raise the plasma GH level, suggesting that the mixture might promote substance metabolism and growth development in goats, 
along with improving immunologic function. The hypothalamic-pituitary-thyroid axis (HPT axis), which involves thyrotropin-releasing hormone from the hypothalamus, TSH from the anterior pituitary gland, and thyroid hormones $\left(T_{3}\right.$ and $\left.T_{4}\right)$ from the thyroid gland, is part of the endocrine system, which is responsible for the regulation of metabolism (Hoermann et al., 2010). Although the plasma $\mathrm{T}_{4}$ level tended to rise, the $\mathrm{CHM}$ mixture failed to regulate the HPT axis because of the relatively inactive property of $\mathrm{T}_{4}$ and no difference occurring for $\mathrm{TSH}$ and $\mathrm{T}_{3}$ in response to the $\mathrm{CHM}$ mixture. The interactions among three endocrine glands, such as the hypothalamus, pituitary gland and adrenal gland, constitute the hypothalamic-pituitary-adrenal axis (HPA axis), a major part of the neuroendocrine system, which controls reactions to stress and regulates many body processes (Kim et al., 2013). Experimental studies have investigated many types of stress, and their effects on the HPA axis in many circumstances (Ranabir \& Reetu, 2011). As a reaction to the CHM mixture, the plasma levels of $\mathrm{ACTH}$, cortisol and aldosterone dropped notably, implying that the mixture might exert some controls on the body of goats via the HPA axis, such as decreasing the blood concentrations of metabolites, relieving stress, stabilizing the blood ionic concentrations of potassium and sodium to maintain the homeostasis of extracellular fluid and circulation volume, and so on. Insulin is central to regulating carbohydrate and fat metabolism in the body, which lowers blood glucose level (Prosser, 1991). Its effect is opposite to that of glucagon. The $\mathrm{CHM}$ mixture tended to raise the plasma insulin level, showing that the mixture might reduce the blood glucose level. Leptin is an adipocyte-derived hormone that acts as a major regulator for feed intake and energy homeostasis. Its biological functions have expanded from antiobesity to broad effects on reproduction, hematopoiesis, angiogenesis, blood pressure, bone mass, lymphoid organ homeostasis and T lymphocyte systems (Zhang et al., 2005). The CHM mixture prominently elevated the plasma leptin level, revealing that the mixture might have some positive effects on lipid metabolism, the alimentary system and the immune system in goats. In addition, from the results of plasma hormone levels in the present study, it might be inferred that the nutrient utilization and the immune function of goats might be ameliorated with the dietary supplementation of the CHM mixture, which has been reflected in beneficial changes in the plasma parameters of immunity and antioxidation, as well as the plasma concentrations of some metabolites in goats.

The enzymatic activity in the blood is linked strongly to the functional status of corresponding tissues that secrete enzymes (Prosser, 1991). Generally, enzymes exist in the blood with relatively constant activity, but this activity can fluctuate with certain changes suffered by the related tissue. Plasma ALT activity is most commonly associated with the liver, and is often measured clinically as part of a diagnostic evaluation of hepatocellular injury to determine liver health (Ghouri et al., 2010). Plasma ALT activity declined significantly with the added CHM mixture, suggesting that the mixture might protect the liver of goats from damage. Creatine kinase $(\mathrm{CK})$ catalyses the conversion of creatine and uses adenosine triphosphate (ATP) to generate phosphocreatine (PCr) and adenosine diphosphate (ADP). This CK enzyme reaction is invertible and thus ATP can be created from PCr and ADP. In tissues and cells that consume ATP rapidly, especially skeletal muscle, PCr acts as energy reservoir for the rapid buffering and revivification of ATP, as well as for intracellular energy transport by the PCr shuttle or circuit (Hekimsoy \& Oktem, 2005). The pronounced reduction of plasma $\mathrm{CK}$ activity with the addition of $\mathrm{CHM}$ mixture illustrated that the mixture might benefit the energy supply of muscle as well as prevent cacotrophy in goats. The enzyme LDH is found extensively in body tissues. As a marker of common injuries and disease, it is released during tissue damage. Specially, the feedback inhibition of LDH can decrease the rate of conversion of pyruvate to lactate at a high lactate concentration (Selwood \& Jaffe, 2012). The significant drop of plasma LDH activity in response to the CHM mixture displayed that the mixture might prevent the accumulation of lactic acid in the blood, and protect body tissues or blood cell from injuries.

Intercommunication and intercoordination between the nervous system, endocrine system and immune system form the neuro-endocrine-immunity net (NEI net), which realizes the advanced integration of various functional activities in the body. Many hormones participate in the modulation of immune function (Prosser, 1991). In the present study, the results of plasma hormone levels indicated that the CHM mixture had the ability to enhance the immune function of goats. Moreover, the immunomodulation of the mixture could be confirmed by the relative results of plasma immune parameters. As the important parts of humoral immunity, the antibody system and the complement system service the innate immune system, and can be recruited and brought into action by the adaptive immune system (Rus \& Niculescu, 2005). C-reactive protein (CRP) is an acute-phase protein that is found in the plasma. Its physiological role is to bind to phosphocholine expressed on the surface of dead or dying cells (and some types of bacteria) to activate the complement system (Mantovani et al., 2008). The distinctly rising concentrations of total protein, albumin, globulin, CRP, Ig A/G/M and complement 3/4 in the plasma exhibited the immunopotentiating effect of the CHM mixture on goats, such as increasing antigen-specific antibody production, activating B cell and macrophages, inducing $T$ cell proliferation and affecting cytokine productions. Nitric oxide synthase (NOS) may catalyse the production of NO from L-arginine. NO is an important cellular signalling molecule with the 
property of free radical involved in many physiological and pathological processes (Culotta \& Koshland, 1992). In response to the CHM mixture, the pronounced enhancement of plasma NOS activity, along with an increasing trend in plasma NO concentration, indicated that the mixture might exert potent mediated effects on goats from the point of neuroscience, physiology and immunology.

The immunity status in the animal body is linked reciprocally to oxidative stress and the ingestion of antioxidants, because free radicals play important roles in immunity and signal transduction (Miyazaki et al., 2001). The excessive free radicals generated by an animal body in an abnormal state could attack polyunsaturated fatty acid and cause lipid peroxidation in the cell membrane (Turner et al., 2004). There is a balance between the production and removal of free radicals in the body. The overproduction of free radicals could be eliminated by antioxidative enzymes including GSH-Px, SOD and catalase. Thus, the antioxidative function, expressed as total $A O C$ and $-\mathrm{OH}$, could be evaluated with increasing activities of GSH-Px, SOD and catalase. Maleic dialdehyde (MDA), as a metabolite of lipid peroxidation in the body, could assess oxidative damage to membranes and reflect free radical-mediated cell membrane damage (Lykkesfeldt, 2007). According to the antioxidative parameters measured in the present study, the CHM mixture might improve the ability of scavenging excessive free radicals, then accentuate the antioxidative function in goats. Reduced plasma cortisol concentrations of wethers fed the CHM mixture support the effects of the mixture on the regulation of antioxidant status.

Concentrations of other plasma metabolites determined in the present study could be used to assess glucose, lipid and $\mathrm{N}$ metabolism (Hosoda et al., 2006). It could be inferred from the corresponding results that the CHM mixture might improve glucose and $\mathrm{N}$ metabolism of goats, but had no effects on the lipid metabolism, which could gain support from the relative plasma hormones or enzymes analysed in the present study.

\section{Conclusions}

The dietary supplementation of CHM mixture exerted some positive regulating effects on the nervous system, the endocrine system and the immune system of goats, thus improving the functions of immunity and antioxidation, as well as the digestion and metabolism of nutrients. In addition, the CHM mixture did not affect the rumen fermentation patterns of goats. More studies are required to screen the optimal dose of CHM mixture, to specify the chemical nature of the active compounds responsible for such effects, and to testify the usefulness and applicability under diverse practical conditions. Furthermore, they need to study the individual effects of the CHM components.

\section{Acknowledgments}

This work was supported financially in part by Fundamental Research Funds for the Central Universities (XDJK2014C154).

\section{Authors' Contributions}

The authors contributed equally to this work.

\section{Conflict of Interest Declaration}

There is no conflict of interest.

\section{References}

Agarwal, N., Agarwal, I., Kamra, D.N. \& Chaudhury, L.C., 2000. Diurnal variations in the activities of hydrolytic enzymes in different fractions of rumen contents of Murrah buffaloes. J. App. Anim. Res. 18, 73-80.

AOAC, 2005. Official Methods of Analysis of AOAC International (18th ed.). Association of Official Analytical Chemists, Arlington VA, Gaithersburg, MD, USA.

Baillie, J.K., 2008. Simple, easily memorised "rules of thumb" for the rapid assessment of physiological compensation for acid-base disorders. Thorax 63, 289-290.

Benchaar, C., Petit, H.V., Berthiaume, R., Whyte, T.D. \& Chouinard, P.Y., 2006. Effects of dietary addition of essential oils and monensin premix on digestion, ruminal fermentation characteristics milk production, and milk composition in dairy cows. J. Dairy Sci. 89, 4352-4364.

Bodas, R., Prieto, N., García-González, R., Andrés, S., Giráldez, F.J. \& López, S., 2012. Manipulation of rumen fermentation and methane production with plant secondary metabolites. Anim. Feed Sci. Technol. 176, 78-93.

Cardozo, P., Calsamiglia, S., Ferret, A. \& Kamel, C., 2005. Screening for the effects of natural plant extracts at different $\mathrm{pH}$ on in vitro rumen microbial fermentation of a high-concentrate diet for beef cattle. J. Anim. Sci. 83, 2572-2579.

Castillejos, L., Calsamiglia, S., Ferret, A. \& Losa, R., 2005. Effects of a specific blend of essential oil compounds and the type of diet on rumen microbial fermentation and nutrient flow from a continuous culture system. Anim. Feed Sci. Technol. 119, 29-41.

Castillejos, L., Calsamiglia, S., Ferret, A. \& Losa, R., 2007. Effects of dose and adaptation time of a specific blend of essential oil compounds on rumen fermentation. Anim. Feed Sci. Technol. 132, 186-201.

Chaney, A.L. \& Marbach, E.P., 1962. Modified reagents for determination of urea and ammonia. Clin. Chem. 8, $130-132$. 
Chinese Pharmacopoeia Commission (ChPC), 2010. Pharmacopoeia of the People's Republic of China (2010 ed.). China Medical Science Press, Beijing, China. (in Chinese).

Culotta, E. \& Koshland, D.E.J., 1992. No news is good news. Science 258, 1862-1864.

Durmic, Z. \& Blache, D., 2012. Bioactive plants and plant products: Effects on animal function, health and welfare. Anim. Feed Sci. Technol. 176, 150-162.

Ghouri, N., Preiss, D. \& Sattar, N., 2010. Liver enzymes, nonalcoholic fatty liver disease, and incident cardiovascular disease: a narrative review and clinical perspective of prospective data. Hepatology 52, 1156-1161.

Greathead, H., 2003. Plants and plant extracts for improving animal productivity. Proc. Nutr. Soc. 62, 279-290.

Hart, K.J., Yáñez-Ruiz, D.R., Duval, S.M., McEwan, N.R. \& Newbold, C.J., 2008. Plant extracts to manipulate rumen fermentation. Anim. Feed Sci. Technol. 147, 8-35.

Hekimsoy, Z. \& Oktem, I.K., 2005. Serum creatine kinase levels in overt and subclinical hypothyroidism. Endocr. Res. 31, 171-175.

Hoermann, R., Eckl, W., Hoermann, C. \& Larisch, R., 2010. Complex relationship between free thyroxine and TSH in the regulation of thyroid function. Eur. J. Endocrinol. 162, 1123-1129.

Hosoda, K., Kuramoto, K., Eruden, B., Nishida, T. \& Shioya, S., 2006. The effects of three herbs as feed supplements on blood metabolites, hormones, antioxidant activity, IgG concentration, and ruminal fermentation in Holstein steers. Asian-Austral. J. Anim. Sci. 19, 35-41.

Jouany, J.P., 1982. Volatile fatty acid and alcohol determination in digestive contents, silage juices, bacterial cultures and anaerobic fermentor contents. Sci. Alim. 2, 131-144.

Kim, J.E., Cho, B.K., Cho, D.H. \& Park, H.J., 2013. Expression of hypothalamic-pituitary-adrenal axis in common skin diseases: evidence of its association with stress-related disease activity. Acta Derm. Venereol. 93, 387-393

Liu, H., Bravata, D.M., Olkin, I., Nayak, S., Roberts, B., Garber, A.M. \& Hoffman, A.R., 2007. Systematic review: The safety and efficacy of growth hormone in the healthy elderly. Ann. Intern. Med. 146, 104-115.

Liu, H.W., Tong, J.M. \& Zhou, D.W., 2011. Utilization of Chinese herbal feed additives in animal production. Agr. Sci. China 10, 1262-1272.

Liu, Z.J. \& Xu, J.Q., 2011. Traditional Chinese Veterinary Medicine (4th ed.). China Agriculture Press, Beijing, China. (in Chinese).

Lowe, S.E., Theodorou, M.K. \& Trinci, A.P.J., 1987. Cellulases and xylanase of anaerobic rumen fungus grown on wheat straw, wheat straw holocellulose, cellulose, and xylan. Appl. Environ. Microbiol. 53, 1216-1223.

Lu, C.D., 2011. Nutritionally related strategies for organic goat production. Small Rumin. Res. 98, 73-82.

Lykkesfeldt, J., 2007. Malondialdehyde as biomarker of oxidative damage to lipids caused by smoking. Clin. Chim. Acta 380, 50-58.

Mantovani, A., Garlanda, C., Doni, A. \& Bottazzi, B., 2008. Pentraxins in innate immunity: from C-reactive protein to the long pentraxin PTX3. J. Clin. Immunol. 28, 1-13.

Manyuchi, B., Ørskov, E.R. \& Kay, R.N.B., 1992. Effects of feeding small amounts of ammonia treated straw on degradation rate and intake of untreated straw. Anim. Feed Sci. Technol. 38, 293-304.

McIntosh, F.M., Williams, P., Losa, R., Wallace, R.J., Beever, D.A. \& Newbold, C.J., 2003. Effects of essential oils on ruminal microorganisms and their protein metabolism. Appl. Environ. Microbiol. 69, 5011-5014.

Mertens, D.R., 1997. Creating a system for meeting the fibre requirements of dairy cows. J. Dairy Sci. 80, $1463-1481$.

Miller, G.L., 1959. Use of dinitrosalicylic acid reagent for determination of reducing sugar. Anal. Chem. 31, 426-428.

Ministry of Agriculture (MOA), 2004. Feeding Standard of Meat-producing Sheep and Goats (NY/T 816-2004). China Agricultural Press, Beijing, China. (in Chinese).

Miron, J., Ben-Ghedalia, D. \& Morrison, M., 2001. Adhesion mechanisms of rumen cellulolytic bacteria. J. Dairy Sci. 84, 1294-1309.

Miyazaki, Y., Yamasaki, M., Mishima, H., Mansho, K., Tachibana, H. \& Yamada, K., 2001. Oxidative stress by visible light irradiation suppresses immunoglobulin production in mouse spleen lymphocytes. Biosci. Biotechnol. Biochem. 65, 593-598.

Montagne, L., Pluske, J.R. \& Hampson, D.J., 2003. A review of interactions between dietary fibre and the intestinal mucosa, and their consequences on digestive health in young non-ruminant animals. Anim. Feed Sci. Technol. 108, 95-117.

Newbold, C.J., McIntosh, F.M., Williams, P., Losa, R. \& Wallace, R.J., 2004. Effects of a specific blend of essential oil compounds on rumen fermentation. Anim. Feed Sci. Technol. 114, 105-112.

NRC, 2007. Nutrient Requirements of Small Ruminants: Sheep, Goats, Cervids, and New World Camelids. National Research Council, National Academies Press, Washington, DC, USA.

Ørskov, E.R. \& McDonald, I., 1979. The estimation of protein disappearance in the rumen from incubation measurements weighted according to rate of passage. J. Agric. Sci., Camb. 92, 499-503.

Patra, A.K. \& Saxena, J., 2010. A new perspective on the use of plant secondary metabolites to inhibit methanogenesis in the rumen. Phytochemistry 71, 1198-1222.

Pitt, R.E., Van Kessel, J.S., Fox, D.G., Pell, A.N., Barry, M.C. \& Van Soest, P.J., 1996. Prediction of ruminal volatile fatty acids and $\mathrm{pH}$ within the net carbohydrate and protein system. J. Anim. Sci. 74, 226-244.

Prosser, C.L., 1991. Comparative Animal Physiology: Environmental and Metabolic Animal Physiology. (4th ed.). WileyLiss, New York, USA.

Ranabir, S. \& Reetu, K., 2011. Stress and hormones. Indian J. Endocrinol. Metab. 15, 18-22.

Rus, H., Cudrici, C. \& Niculescu, F., 2005. The role of the complement system in innate immunity. Immunol. Res. 33, 103-112.

Russell, J.B. \& Wilson, D.B., 1996. Why are ruminal cellulolytic bacteria unable to digest cellulose at low pH? J. Dairy Sci. 
79, 1503-1509.

SAS, 2005. Statistical Analysis Systems Users Guide, SAS Online Doc version 9.1.3. SAS Institute. Inc., Cary, N.C., USA.

Selwood, T. \& Jaffe, E.K., 2012. Dynamic dissociating homo-oligomers and the control of protein function. Arch. Biochem. Biophys. 519, 131-143.

Spanghero, M., Zanfi, C., Fabbro, E., Scicutella, N. \& Camellini, C., 2008. Effects of a blend of essential oils on some end products of in vitro rumen fermentation. Anim. Feed Sci. Technol. 145, 364-374.

Turner, R., Baron, T., Wolffram, S., Minihane, A.M., Cassidy, A., Rimbach, G. \& Weinberg, P.D., 2004. Effect of circulating forms of soy isoflavones on the oxidation of low density lipoprotein. Free Radical Res. 38, 209-216.

Van Soest, P.J., Robertson, J.B. \& Lewis, B.A., 1991. Methods for dietary fibre, neutral detergent fibre, and nonstarch polysaccharides in relation to animal nutrition. J. Dairy Sci. 74, 3583-3597.

Vanzant, E.S., Cochran, R.C. \& Titgemeyer, E.C., 1998. Standardization of in situ techniques for ruminant feedstuff evaluation. J. Anim. Sci. 76, 2717-2729.

Wallace, R.J., 2004. Antimicrobial properties of plant secondary metabolites. P. Nutr. Soc. 63, 621-629.

Wang, S.P., Wang, W.J., Zuo, F.Y. \& Zhang, J.H., 2010. The study on degradation characteristics for dry matter and crude protein of the familiar feedstuffs in the rumen of Dazu black goats. Chin. J. Anim. Sci. 21, 47-52. (in Chinese, English abstract).

Wood, T.M. \& Bhat, K.M., 1988. Methods for measuring cellulase activities. Methods Enzymol. 160, 87-130.

Zhang, F., Chen, Y., Heiman, M. \& Dimarchi, R., 2005. Leptin: structure, function and biology. Vitam. Horm. 71, 345-372. 